\title{
Reconstruction and analysis of erythemal UV radiation time series from Hradec Králové (Czech Republic) over the past 50 years
}

\author{
Klára Č́žžková ${ }^{1,2}$, Kamil Láska ${ }^{1}$, Ladislav Metelka ${ }^{2}$, and Martin Staněk ${ }^{2}$ \\ ${ }^{1}$ Department of Geography, Faculty of Science, Masaryk University, Brno, 611 37, Czech Republic \\ ${ }^{2}$ Solar and Ozone Observatory, Czech Hydrometeorological Institute, Hradec Králové, 500 08, Czech Republic \\ Correspondence: Klára Čížková (cizkova.klara@hotmail.com)
}

Received: 27 July 2017 - Discussion started: 4 September 2017

Revised: 21 December 2017 - Accepted: 21 December 2017 - Published: 7 February 2018

\begin{abstract}
This paper evaluates the variability of erythemal ultraviolet (EUV) radiation from Hradec Králové (Czech Republic) in the period 1964-2013. The EUV radiation time series was reconstructed using a radiative transfer model and additional empirical relationships, with the final root mean square error of $9.9 \%$. The reconstructed time series documented the increase in EUV radiation doses in the 1980s and the 1990 s (up to $15 \%$ per decade), which was linked to the steep decline in total ozone ( $10 \%$ per decade). The changes in cloud cover were the major factor affecting the EUV radiation doses especially in the 1960s, 1970s, and at the beginning of the new millennium. The mean annual EUV radiation doses in the decade 2004-2013 declined by $5 \%$. The factors affecting the EUV radiation doses differed also according to the chosen integration period (daily, monthly, and annually): solar zenith angle was the most important for daily doses, cloud cover, and surface UV albedo for their monthly means, and the annual means of EUV radiation doses were most influenced by total ozone column. The number of days with very high EUV radiation doses increased by $22 \%$ per decade, the increase was statistically significant in all seasons except autumn. The occurrence of the days with very high EUV doses was influenced mostly by low total ozone column ( $82 \%$ of days), clear-sky or partly cloudy conditions ( $74 \%$ of days) and by increased surface albedo (19\% of days). The principal component analysis documented that the occurrence of days with very high EUV radiation doses was much affected by the positive phase of North Atlantic Oscillation with an Azores High promontory reaching over central Europe. In the stratosphere, a strong Arctic circumpolar vortex and the meridional inflow of ozone-poor air from the southwest were favorable for the occurrence of days with
\end{abstract}

very high EUV radiation doses. This is the first analysis of the relationship between the high EUV radiation doses and macroscale circulation patterns, and therefore more attention should be given also to other dynamical variables that may affect the solar UV radiation on the Earth surface.

\section{Introduction}

Solar ultraviolet (UV) radiation causes a wide variety of environmental and health effects, including the deceleration of the rate of photosynthesis, damage of DNA structures, and the increased risk of skin cancer in humans (e.g., Diffey, 1991; Caldwell, 2007). The scientific interest in solar UV radiation has significantly increased since the 1980 s, when it was discovered that the many adverse environmental and health effects of the solar ultraviolet (UV) radiation had been reinforced by the thinning of the ozone layer (e.g., Farman et al., 1985; Krzyscin and Borkowski, 2008). The effects of UV radiation on human skin differ according to the wavelength, so the erythema action spectrum (McKinlay and Diffey, 1987) was developed to model the susceptibility of human skin to sunburn. Therefore, it is important to assess the changes in the erythemal ultraviolet (EUV) radiation over a longer period of time and relate them to processes and events that are involved in the attenuation of solar radiation passing through the atmosphere (Lucas et al., 2006).

The incident UV irradiance is affected by a broad range of atmospheric and environmental factors, of which the total ozone column (TOC) is arguably the most studied one. Ozone, together with molecular oxygen, absorbs all UV-C and a part of UV-B radiation, which are the most harmful 
ones to organisms (Bais, 2015). The changes in UV radiation are further modulated by cloudiness and cloud types, atmospheric aerosols, solar zenith angle, and the altitude and ground surface characteristics of the location (Kerr, 2005). According to numerous studies, atmospheric circulation and stratospheric temperature greatly affect the intensity of global ozone losses (e.g., Orsolini and Limpasuvan, 2001; Schnadt and Dameris, 2003; Hofmann et al., 2009). In the 1970s-1990s, TOC trends in central Europe showed a decline by about $3-4 \%$ per decade, especially in spring, while the recovery of the ozone layer has been reported since the end of the 1990s (e.g., Krzyścin et al., 1998; Krzyscin and Borkowski, 2008; Vaníček et al., 2012; De Bock et al., 2014).

So far, the analyses of EUV radiation trends have been carried out in different locations across the Northern Hemisphere. A major increase in EUV radiation doses was observed in the 1980s and 1990s, and according to Ziemke et al. (2000), the trends ranged from $4.5 \%$ per decade in the Mediterranean region to $8.6 \%$ per decade in East Asia. The studies from central Europe reported an increase in EUV daily doses ranging from 2 to $17 \%$ per decade (Rieder et al., 2008), but most commonly between 5 and $6 \%$ per decade (e.g., Den Outer et al., 2010; Krzyścin et al., 2011). According to Rieder et al. (2008), two-thirds of the ascertained trends were attributed to the changes in TOC, and the remaining one-third to the combined decrease in cloudiness and aerosol optical depth. In spite of the ozone layer recovery since the mid-1990s, this period does not reveal any statistically significant changes in EUV irradiation (Hadzimustafic et al., 2013). At the same time, an estimate of future trend in UV radiation remains unclear because it is often overlaid by the influence of cloudiness and aerosols, whose trends significantly vary at different European sites (Bais et al., 2015).

The solar UV radiation reaching the Earth's surface can be measured either by broadband or narrowband UV radiometers, or by spectrophotometers, like the Brewer spectrophotometer. Unlike the broadband radiometers, the Brewer spectrophotometer provides the most accurate UV radiation observations and it is therefore considered a reference instrument (e.g., Gardiner et al., 1993; Anav et al., 1996; Hülsen et al., 2008). Nevertheless, the UV radiation measurements taken by the Brewer spectrophotometers are sparse and often cover only a short period of time, which complicates their incorporation into the evaluation of long-term trends and effects on human health (Rieder et al., 2008). Therefore, in order to assess the UV radiation variability in the past, time series reconstructions are essential. In central Europe, several UV radiation reconstructions have recently been performed (e.g., Krzyscin et al., 2004; Rieder et al., 2008; Den Outer et al., 2010); however, the reconstructed time series analyses do not extend to the last decade.

The EUV radiation time series presented in this study covers five decades (1964-2013) and uses radiative transfer modeling and the most precise EUV radiation measurements available in Hradec Králové (Czech Republic). The evalua- tion of the reconstructed time series for the given location focused on (1) the long-term variability and trends in EUV radiation, (2) the relationships between EUV radiation doses, TOC, and cloud cover, and (3) the days with very high EUV radiation daily doses and their relationship to large-scale atmospheric circulation patterns.

\section{Study site}

The data used in this study have been obtained at the Solar and Ozone Observatory of the Czech Hydrometeorological Institute, which has been operating since 1951 and focuses mostly on ozone and solar radiation measurements (Vaníček, 2001). The observatory is situated on a small hill in the south of Hradec Králové $\left(50.180^{\circ} \mathrm{N}, 15.833^{\circ} \mathrm{E}\right)$ at an altitude of $285 \mathrm{~m}$ a.s.l. The building stands away from local pollution sources and the southern horizon is open. During the studied period (1964-2013), the localization of the station was not altered and, except from the change of the instruments, there are no other known sources of data inhomogeneity. All the instruments installed at the Hradec Králové observatory are described in Vaníček (2001) and Vaníček et al. (2015) and have been calibrated regularly according to the standards corresponding to the Guide to Meteorological Instruments and Methods of Observations, World Meteorological Organization (WMO, 2014).

\section{Erythemal UV radiation time series reconstruction}

\subsection{Input data}

The measurements of UV radiation at the Hradec Králové observatory started in 1994 (Vaníček, 2001), so in order to analyze the five-decade-long time series, the EUV radiation time series had to be reconstructed. As input, total ozone column (TOC), atmospheric optical depth (AOD), surface albedo, water vapor column, and global radiation from the Hradec Králové observatory have been used.

\subsubsection{Total ozone column}

TOC is one of the most important variables affecting the intensities of EUV radiation. The mean daily TOC values for the period 1964-2013 were compiled from the Brewer spectrophotometer MK-IV B098 and the Dobson spectrophotometer D074 measurements. The missing values (approximately $16 \%$ of all days) were estimated from ERA-40 and ERA-Interim reanalysis datasets (Uppala et al., 2005; Dee et al., 2011). Related instruments and the method used for the mean daily TOC time series completion are described in Vaníček et al. (2012). 


\subsubsection{Aerosol optical depth}

Since there are no long-term atmospheric aerosol observations at the study site, annual climatological cycles of AOD were constructed based on the existing records. This method can approximate the climatological behavior of aerosols, but it does not consider any yearly variations (Lindfors et al., 2007). The mean daily AOD values for $\lambda=320 \mathrm{~nm}$ $\left(\mathrm{AOD}_{320}\right)$ were measured by the Brewer spectrophotometer MK-III B184 in the period 2005-2013. The mean daily AOD values for $\lambda=550 \mathrm{~nm}\left(\mathrm{AOD}_{550}\right)$ for the period 20012013 were obtained from the Moderate Resolution Imaging Spectroradiometer (MODIS) (Remer et al., 2005). The total amount of days with assigned AOD values, from which the climatological cycle was calculated, was $61 \%$ for $\mathrm{AOD}_{320}$, and $46 \%$ for $\mathrm{AOD}_{550}$.

\subsubsection{Surface albedo}

Surface albedo is a very important variable determining the intensity of solar UV radiation. In winter months, surface albedo changes may increase the intensity of solar UV radiation by up to 20-30\% (Blumthaler and Ambach, 1988; Krzyścin et al., 2004). The mean daily surface albedo for shortwave radiation in the period 1964-2013 was calculated using an ensemble of multilayer perceptron neural networks with the observed state of the surface as the single relevant predictor and the measured shortwave albedo as the predictand. Only the data from noon hours were used, and the possible annual course of the relationship was taken into account with the help of circular neurons added to the input layer. Data from the period 2000-2014 (4269 cases) were used to develop the model, while being randomly divided into training set (70\% of data entries), testing set (15\%), and validation set $(15 \%)$. The trained network was then applied to estimate the albedo in the period 1964-1999, when the measured shortwave albedo was not available. The shortwave albedo was then transferred to the albedo for UV radiation using Eq. (1). The coefficients were estimated based on the shortwave albedo for different states of the surface, because for most surfaces, UV albedo is very low but for snow-covered surfaces it approaches the values of shortwave albedo (Feister and Grewe, 1995; De Paula Corrêa and Ceballos, 2008).

$$
\mathrm{ALB}_{\mathrm{UV}}= \begin{cases}0.05 & \text { for } \mathrm{ALB}_{\mathrm{SW}}<0.21 \\ 1.36 \mathrm{ALB}_{\mathrm{SW}}-0.24 & \text { for } 0.21 \leq \mathrm{ALB} \mathrm{B}_{\mathrm{SW}} \leq 0.65, \\ \mathrm{ALB}_{\mathrm{SW}} & \text { for ALB } \mathrm{ALW}>0.65\end{cases}
$$

where $\mathrm{ALB}_{\mathrm{UV}}$ is the surface albedo for UV radiation and $A L B_{S W}$ is the surface albedo for shortwave radiation.

\subsubsection{Water vapor column}

Atmospheric water vapor absorbs a significant part of the global solar radiation (e.g., Solomon et al., 1998); therefore, the total water vapor column was also taken into account when performing the radiative transfer calculations.
The daily means of water vapor column in the period 19642013 were obtained from the ERA-40 and ERA-Interim reanalysis datasets.

\subsubsection{Solar radiation}

Global solar radiation was used in the EUV radiation time series reconstruction in order to estimate the cloud effects on EUV radiation (e.g., Schwander et al., 2002). In the period 1964-2013, the global radiation was measured using the CM5 and CM11 pyranometers by Kipp \& Zonen (Vaníček et al., 2015).

At the Hradec Králové observatory, UV radiation has been measured by the Brewer spectrophotometer MK-IV B098 since 1994. In 2004, the double-monochromator Brewer spectrophotometer MK-III B184 was installed. Using the spectroradiometric method, these instruments are able to detect solar UV radiation in the wavelength interval 280$400 \mathrm{~nm}$ (UV-A and UV-B radiation). Both instruments are calibrated regularly every 2 years against the B017 world traveling standard, and the calibration uncertainty is up to $1 \%$ (see, e.g., Vaníček, 2002; Vaníček et al., 2015). The EUV radiation time series obtained by the Brewer spectrophotometer B184 in the period 2005-2013 helped to determine the EUV radiation reconstruction equations and to validate the model (see Sect. 3.2, "Methods and model validation").

\subsection{Methods and model validation}

The reconstruction of the 1964-2013 EUV radiation time series from the Hradec Králové observatory was performed using a radiative transfer model and empirical nonlinear equations. The time series was originally reconstructed with hourly resolution, because better results are achieved when a higher time resolution is applied (Rieder et al., 2008). Then, the EUV radiation daily doses were calculated from the reconstructed data.

First, the clear-sky EUV and global radiation were modeled using the DISORT solver of the libRadtran radiative transfer package (Mayer and Kylling, 2005). The input parameters contained the information on the location (latitude, longitude and altitude), TOC, albedo, annual climatological cycles of atmospheric aerosols $\left(\mathrm{AOD}_{320}\right.$ and $\left.\mathrm{AOD}_{550}\right)$, and, in the case of clear-sky global radiation simulation, total water vapor column.

The all-sky EUV radiation was calculated based on global radiation measurements, which is a common method for reconstructing UV radiation doses (e.g., Krzyscin et al., 2004; Lindfors et al., 2007; Rieder et al., 2008). The reconstruction was based on the cloud modification factor $\left(\mathrm{CMF}_{\mathrm{EUV}}\right)$, which is the ratio between cloudy-sky EUV radiation $\left(E V_{\text {cloud }}\right)$ and clear-sky EUV radiation $\left(E V_{\text {clear }}\right)$, as shown in Eq. (2). Correspondingly, the CMF for global radiation $\left(\mathrm{CMF}_{\mathrm{GLB}}\right)$ was calculated as the ratio between cloudysky $\left(\mathrm{GLB}_{\text {cloud }}\right)$ and clear-sky global radiation $\left(\mathrm{GLB}_{\text {clear }}\right)$, as 
shown in Eq. (3) (Lindfors et al., 2007).

$$
\begin{aligned}
\mathrm{CMF}_{\mathrm{EUV}} & =\frac{\mathrm{EUV}_{\text {cloud }}}{\mathrm{EUV}_{\text {clear }}} \\
\mathrm{CMF}_{\mathrm{GLB}} & =\frac{\mathrm{GLB}_{\text {cloud }}}{\mathrm{GLB}_{\text {clear }}}
\end{aligned}
$$

Therefore, the reconstructed all sky EUV radiation $\left(\mathrm{EUV}_{\mathrm{rec}}\right)$ can be expressed as the modeled EUV $_{\text {clear }}$ multiplied by $\mathrm{CMF}_{\text {EUV }}$. $\mathrm{CMF}_{\mathrm{EUV}}$ was obtained using the global radiation observations, since it can be expressed as the function of $\mathrm{CMF}_{\mathrm{GLB}}$ and solar zenith angle (SZA) (e.g., Lindfors et al., 2007; Bilbao et al., 2011). To obtain the best-fit function and to minimize the RMSE, a multiple nonlinear regression expression, shown in Eq. (4), was used. The coefficients used to calculate $\mathrm{CMF}_{\mathrm{EUV}}$ are given in Table 1 .

$$
\begin{array}{r}
\mathrm{CMF}_{\mathrm{EUV}}=\left[(a+b \mathrm{SZA}) \mathrm{CMF}_{\mathrm{GLB}}^{(c+d \mathrm{SZA})}\right] \\
\cdot\left(k+l \mathrm{CMF}_{\mathrm{GLB}}+m \mathrm{CMF}_{\mathrm{GLB}}^{2}\right)
\end{array}
$$

The validation of the model outputs was performed using the individual measurements of EUV radiation from the period 2005-2013. The individual records were coupled with the global radiation data, and the entire data set was then randomly split into two independent data sets with roughly the same number of entries. The first data set, which included only observations taken with SZA smaller than $75^{\circ}$, was used to develop the multiple nonlinear regression model for the $\mathrm{CMF}_{\text {EUV }}$ estimation. The second dataset, which was used to test the model, included EUV irradiance values for all SZA values. The irregular time interval between the individual Brewer spectrophotometer EUV irradiation records did not allow for daily doses integration; therefore, in order to evaluate the model performance, the daily mean EUV irradiation was calculated and assessed. Table 2 shows the mean error, the root mean square error and the determination coefficient $r^{2}$ between the reconstructed and observed mean daily EUV radiation for the whole period and for the seasons (spring: MAM; summer: JJA; autumn: SON; winter: DJF). The errors are lowest in summer and highest in winter, while the correlation between measured and reconstructed daily doses is highest in autumn and lowest in winter, but it exceeds $94 \%$ in all seasons. Figure 1 shows the absolute and relative differences between the observed and reconstructed mean daily EUV radiation. Although the absolute differences are small, the relative differences are largest in winter (the mean relative difference makes up to $10 \%$ in February). On the other hand, in spring, summer and autumn, the mean relative differences are in the range of $0-3 \%$, and less than $20 \%$ of values exceed the $10 \%$ difference between the observed and reconstructed daily means.
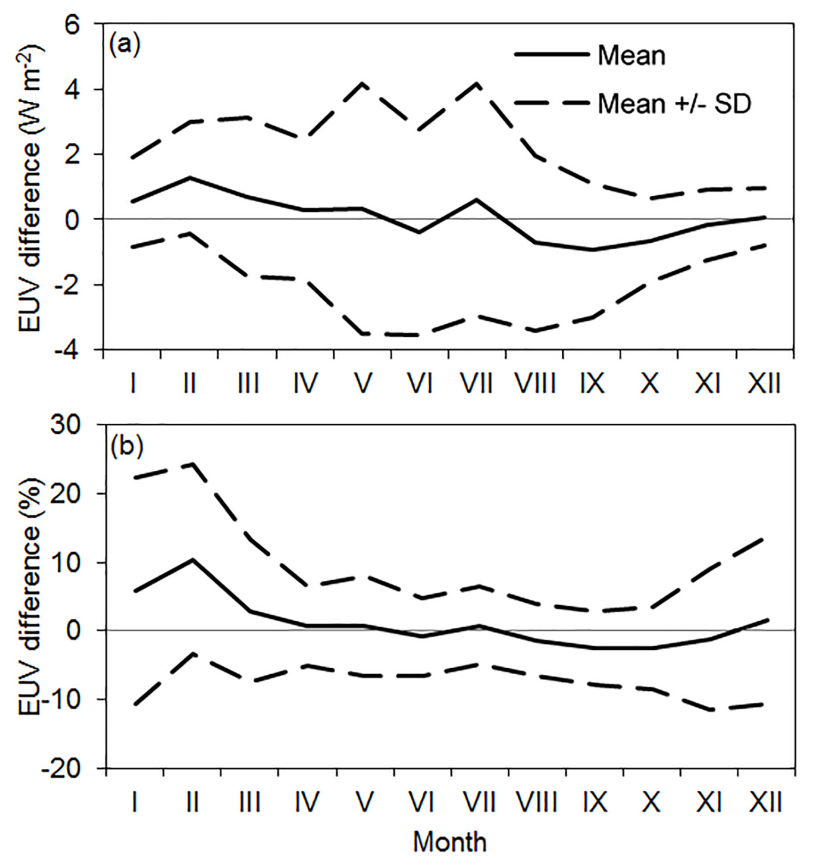

Figure 1. The mean (a) absolute and (b) relative differences between the observed and modeled EUV irradiance and their standard deviations (SD) at the Hradec Králové observatory in the period 2005-2013.

\section{Methods of the time series analysis}

The analysis of the reconstructed 1964-2013 EUV radiation consists of three parts: (1) the annual variations and trends, (2) the factors affecting EUV radiation, and (3) the analysis of days with very high EUV radiation doses. The data were processed using the software STATISTICA ${ }^{\circledR} 10$, R Project for Statistical Computing (R Core Team, 2014), and ArcGIS ${ }^{\circledR} 10$.

To perform the analyses, TOC and surface albedo data (Sect. 3.1) were used. Hourly cloud cover data in octas were included in the analysis in order to evaluate the cloud effects on EUV radiation. There are no cloud cover records directly at the Hradec Králové observatory; therefore, the data from the Hradec Králové, Pouchov synoptic station $\left(50.246^{\circ} \mathrm{N}, 15.843^{\circ} \mathrm{E} ; 243 \mathrm{~m}\right.$ a.s.l.; $8 \mathrm{~km}$ north of the Hradec Králové observatory) were used. The missing values in the time series were supplemented with data from the Pardubice, airport synoptic station (located in flat lowlands at $50.013^{\circ} \mathrm{N}, 150739^{\circ} \mathrm{E} ; 225 \mathrm{~m}$ a.s.l.; $20 \mathrm{~km}$ south of the Hradec Králové observatory). The linear regression relationship between these two datasets was strong and statistically significant $\left(r^{2}=73 \%\right)$. For every day, the weighted mean of cloud cover was calculated, while the weight was set as the mean clear-sky EUV radiation at the certain time of the day. The gaps in the aggregated daily cloud cover time series (7\% of days) were then filled by a nonlinear regression using the 
Table 1. The coefficients used to determine $\mathrm{CMF}_{\mathrm{EUV}}$ based on $\mathrm{CMF}_{\mathrm{GLB}}$ and $\mathrm{SZA}$ by the means of nonlinear regression.

\begin{tabular}{lrrrrrrr}
\hline Coefficient & $a$ & $b$ & $c$ & $d$ & $k$ & $l$ & $m$ \\
\hline Value & 3.8199 & -0.0081 & 1.4502 & -0.0076 & 0.4598 & -0.2771 & 0.0738 \\
\hline
\end{tabular}

Table 2. Mean error (ME) and its percentage value (ME\%), root mean square error (RMSE) and its percentage value (RMSE\%), and the determination coefficient $\left(r^{2}\right)$ for the reconstructed time series and for the individual seasons at the Hradec Králové observatory for 1964-2013.

\begin{tabular}{lrrrrr}
\hline Season & ME & ME\% & RMSE & RMSE $\%$ & $r^{2}(\%)$ \\
\hline Year & 0.05 & 1.01 & 2.47 & 9.93 & 99.1 \\
Spring & 0.44 & 1.43 & 2.93 & 8.28 & 98.2 \\
Summer & -0.17 & -0.46 & 3.21 & 5.66 & 98.0 \\
Autumn & -0.60 & -2.12 & 1.67 & 7.85 & 99.2 \\
Winter & 0.58 & 5.61 & 1.29 & 15.69 & 94.6 \\
\hline
\end{tabular}

Table 3. Threshold values of EUV radiation daily doses for days with $\mathrm{EUV}_{90+}$ in individual months.

\begin{tabular}{lrrrrrr}
\hline Month & I & II & III & IV & V & VI \\
EUV $_{90+}\left(\mathrm{kJ} \mathrm{m}^{-2}\right)$ & 0.30 & 0.65 & 1.31 & 2.39 & 3.36 & 3.97 \\
\hline Month & VII & VIII & IX & X & XI & XII \\
EUV $_{90+}\left(\mathrm{kJ} \mathrm{m}^{-2}\right)$ & 3.92 & 3.22 & 2.09 & 1.08 & 0.38 & 0.26 \\
\hline
\end{tabular}

global radiation daily doses from the Hradec Králové observatory $\left(r^{2}=76 \%\right)$.

The trends in EUV radiation, as well as TOC and cloudiness, were studied using locally weighted scatterplot smoothing (Cleveland, 1979). The current trends in TOC were evaluated using linear regression in the period 1995-2013, which was selected for this assessment because in 1995, total ozone reached its minimum over central Europe (Krzyscin and Borkowski, 2008). The effect of SZA, TOC, cloud cover, and surface UV albedo on EUV radiation daily doses and their monthly and yearly means throughout the entire study period and the five decades was analyzed using partial correlation coefficients $\left(r_{\text {part }}\right)$. The level of statistical significance $\alpha$ was set to 0.05 in all the tests performed in this study.

The emphasis was placed on days with very high EUV radiation doses (days with $\mathrm{EUV}_{90+}$ ). They were defined based on the 90th percentile of the EUV radiation daily doses for each month. Therefore, 1827 days with $\mathrm{EUV}_{90+}$ were selected and further analyzed. The monthly threshold values of $\mathrm{EUV}_{90+}$ for the period 1964-2013 are displayed in Table 3. The days with $\mathrm{EUV}_{90+}$ were then assessed with respect to trends and explained with regards to TOC, cloud cover and surface UV albedo. Low TOC was defined as the 50th percentile of each month and lower. According to AladosArboledas et al. (2003), high intensities of EUV radiation can be observed under the cloud cover of 4 octas or less, therefore, low cloud cover threshold was set to this value. High albedo was set to 0.3 , which is, according to De Paula Corrêa and Ceballos (2008), the lowest albedo of consistent snow cover. The pressure field in the days with $\mathrm{EUV}_{90+}$ was investigated using principal component analysis (Storch and Zwiers, 1999). Two geopotential heights were chosen: $1000 \mathrm{hPa}$, which is well representative of surface pressure, and $70 \mathrm{hPa}$, which is the level near the ozone layer maximum where the ozone changes were most evident (Kirchner and Peters, 2003). The field of geopotential heights for pressure levels 1000 and $70 \mathrm{hPa}$ in the period 1964-2013 was obtained from the NCEP/NCAR reanalysis (Kalnay et al., 1996). The study area was defined as a rectangle between $40^{\circ} \mathrm{W}-40^{\circ} \mathrm{E}$ and $20-70^{\circ} \mathrm{N}$ with a spatial resolution of $2.5^{\circ}$. The daily values of the principal components were then correlated with the Northern Atlantic Oscillation (NAO) and Arctic Oscillation (AO) indices (Wallace and Gutzler, 1981; Thompson and Wallace, 1998). Although NAO and AO are not independent from each other (e.g., Vallis et al., 2004), they are linked to slightly different processes in the atmosphere. While AO is zonally symmetrical and describes mostly the polar vortex, NAO relates mainly to the see-saw variability of the Icelandic Low and Azores High pressure regions (Ambaum et al., 2001). Therefore, in this study, AO and NAO were assessed separately.

\section{Results and discussion}

\subsection{Annual variations and trends}

During the period 1964-2013, the annual means of TOC (Fig. 2a) show a large relative variability (coefficient of variation $c_{\mathrm{v}}=3.5 \%$ ) with diverse trends in the individual decades (Table 4). In the 1960s and 1970s, the annual mean TOC at the Hradec Králové observatory fluctuated between 340 and $360 \mathrm{DU}$. The decline in TOC started at the beginning of the 1980s, reaching the minimum in 1993 following the eruption of Mount Pinatubo (annual mean of 315 DU). Then the TOC fluctuated at lower values than at the beginning of the studied period (320-350 DU). The most distinct decline in TOC was recorded in spring; the weakest decline was observed in autumn (Fig. 2d). From 1995 on, the linear trends in TOC were not statistically significant in any particular month, but there was an increase in winter (January: $1.2 \pm 0.7 \mathrm{DU}$ per year; February: $1.3 \pm 0.9 \mathrm{DU}$ per year) and a decrease in summer (August: $-0.4 \pm 0.4 \mathrm{DU}$ per year). The trends in TOC, which are linked mostly to the increase in 

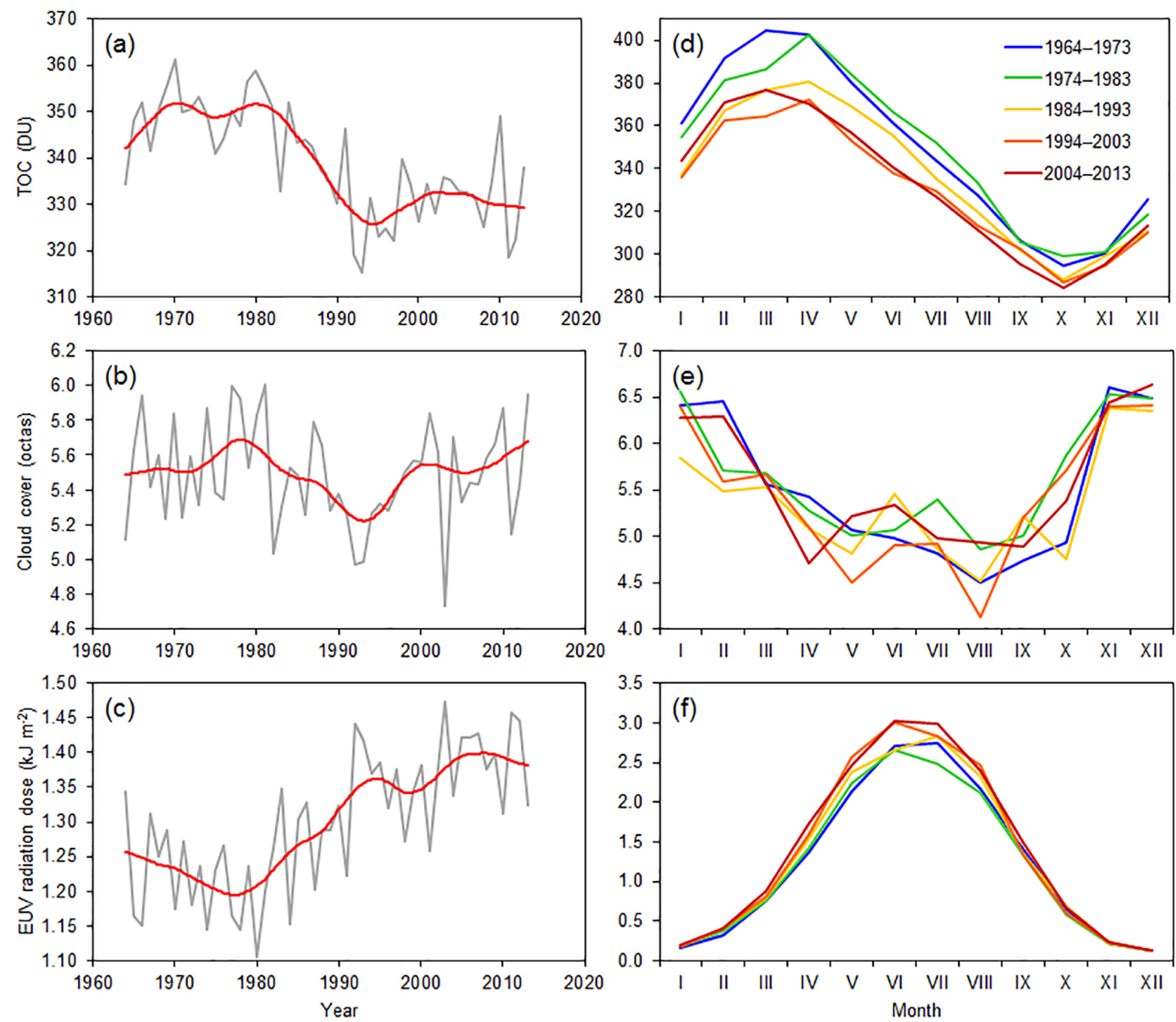

Figure 2. The annual means of (a) TOC, (b) cloud cover, and (c) daily EUV radiation doses fitted with the locally weighted scatterplot smoothing curve (red), and the mean annual variation of (d) TOC, (e) cloud cover, and (f) daily EUV radiation doses at the Hradec Králové observatory in the individual decades of the period 1964-2013.

ozone depleting substances in the stratosphere, but also to the changes of atmospheric dynamics, show a very similar development to other parts of central Europe (e.g., Trepte and Winkler, 2004; Hood and Soukharev, 2005; Harris et al., 2008). The negative trends in warm seasons after 1995 , which can be linked to the changes of circulation patterns affecting the concentration of ozone depleting substances in the atmosphere, were also recorded at other parts of central Europe (Krzyscin and Borkowski, 2008; Vaníček et al., 2012; Krzyścin and Rajewska-Więch, 2015). The annual variation of TOC recorded at the Hradec Králové observatory, with its minima in autumn (October) and maxima in spring (March or April), is connected to the natural variability of TOC in Europe, which is linked to the transport of ozone from low latitudes (Zvyagintsev et al., 2015).

Annual cloud cover means (Fig. 2b) exhibit a larger relative variability than TOC $\left(c_{\mathrm{V}}=5.3 \%\right)$ and changeable trends (Table 4). Cloud cover maxima were recorded in winter (November or December) and minima in summer (August), while in some years there was a secondary maximum present in June or July (attributed to prevailing convection). Over the period 1964-2013, cloud cover did not show any compact trend in any of the months (Fig. 2e). There was a period of high cloud cover during the end of the 1970s and the beginning of the 1980s, which was most pronounced in July and October, with the maximum yearly mean cloud cover in 1981 (6.0 octas). This period was followed by a decrease in cloud cover in the 1990s, which was very distinct in January, May, July, and October. Since the 1990s, the yearly mean cloud cover increased to up to 5.9 octas in 2013. According to Wibig (2008), who observed similar patterns in Poland, the most important factor determining the changes in cloud cover is the variability of the occurrence of different cloud types, for example the intensification of convection in summer months. The changes in the 1990s seem to be driven especially by the decreasing amount of sulfur dioxide emitted into the atmosphere (e.g., Krüger and Graßl, 2002).

Of the three studied variables, the annual mean daily doses of EUV radiation (Fig. 2c) show the largest relative variability $\left(c_{\mathrm{V}}=7.4 \%\right)$. The trends in the annual mean daily doses of EUV radiation were also changing over the study period (Table 4). The EUV radiation doses declined until the end of the 1970s, which might indicate a connection to the increase in cloudiness in this period. In the 1980s and 1990s, the EUV 
Table 4. Linear trends and standard error of annual means of TOC, cloud cover and EUV radiation doses for the individual decades of the period 1964-2013 at the Hradec Králové observatory; asterisks mark statistically significant trends $(\alpha=0.05)$.

\begin{tabular}{rrrr}
\hline Decade & $\begin{array}{r}\text { TOC } \\
(\% \text { per decade })\end{array}$ & $\begin{array}{r}\text { Cloud cover } \\
(\% \text { per decade })\end{array}$ & $\begin{array}{r}\text { EUV doses } \\
(\% \text { per decade })\end{array}$ \\
\hline $1964-1973$ & $4.3 \pm 2.0$ & $-1.2 \pm 5.8$ & $-3.0 \pm 6.0$ \\
$1974-1983$ & $0.2 \pm 2.7$ & $-5.7 \pm 7.1$ & $7.7 \pm 6.0$ \\
$1984-1993$ & $-9.4 \pm 2.4^{*}$ & $-11.1 \pm 4.1^{*}$ & $14.9 \pm 6.1^{*}$ \\
$1994-2003$ & $2.31 \pm 1.9$ & $0.6 \pm 6.3$ & $2.5 \pm 5.4$ \\
$2004-2013$ & $-1.0 \pm 2.9$ & $3.1 \pm 5.2$ & $-0.5 \pm 4.7$ \\
\hline
\end{tabular}

doses increased steeply due to the decrease in TOC, with the maximal mean daily dose of EUV radiation being recorded in 2003. The slight decline in EUV radiation doses since about 2005 was mostly attributed to the changes in cloud cover. The relative increase in EUV radiation doses was most pronounced in spring and summer, less in autumn and winter. The overall changes in EUV radiation doses were not statistically significant in January, September, October, or December. These results are in accord with most other publications focusing on the long-term variability of EUV radiation in central Europe (e.g., Rieder et al., 2008; Den Outer et al., 2010; Krzyścin et al., 2011). The very high EUV radiation doses in 2003, which were caused by the anomalously low cloud cover due to high pressure episodes in summer, were also recorded at other European stations (Den Outer et al., 2010; Rieder et al., 2010). The annual variations of EUV radiation doses, shown in Fig. 2f, are clearly following the changes in SZA with maxima in summer (June, July) and minima in winter (December). The shift of the annual maxima from June to July can be attributed to the annual variations of TOC (Seckmeyer et al., 2008).

\subsection{Factors affecting the erythemal UV radiation doses}

The importance of the factors affecting the EUV radiation doses varied based on the chosen time period, i.e., daily doses and their monthly and annual means. Over the period 19642013, the dominant factor affecting the annual means of EUV radiation daily doses was TOC (partial correlation coefficient $r_{\text {part }}=-0.75$ ), yet the effects of cloud cover and surface UV albedo were also statistically significant $\left(r_{\text {part }}=-0.31\right.$, resp. 0.23). The monthly means of EUV radiation doses were affected mostly by SZA, followed by TOC, surface UV albedo, and cloud cover (Table 5). The effect of observed variables changed during the individual months. In winter (January, February, December), the effect of surface UV albedo was greater than the effect of cloud cover and TOC, whereas in June and August, the monthly means of EUV radiation doses were most affected by TOC. In all other months, cloud cover was the most important factor. As shown in Table 5, the daily doses of EUV radiation were
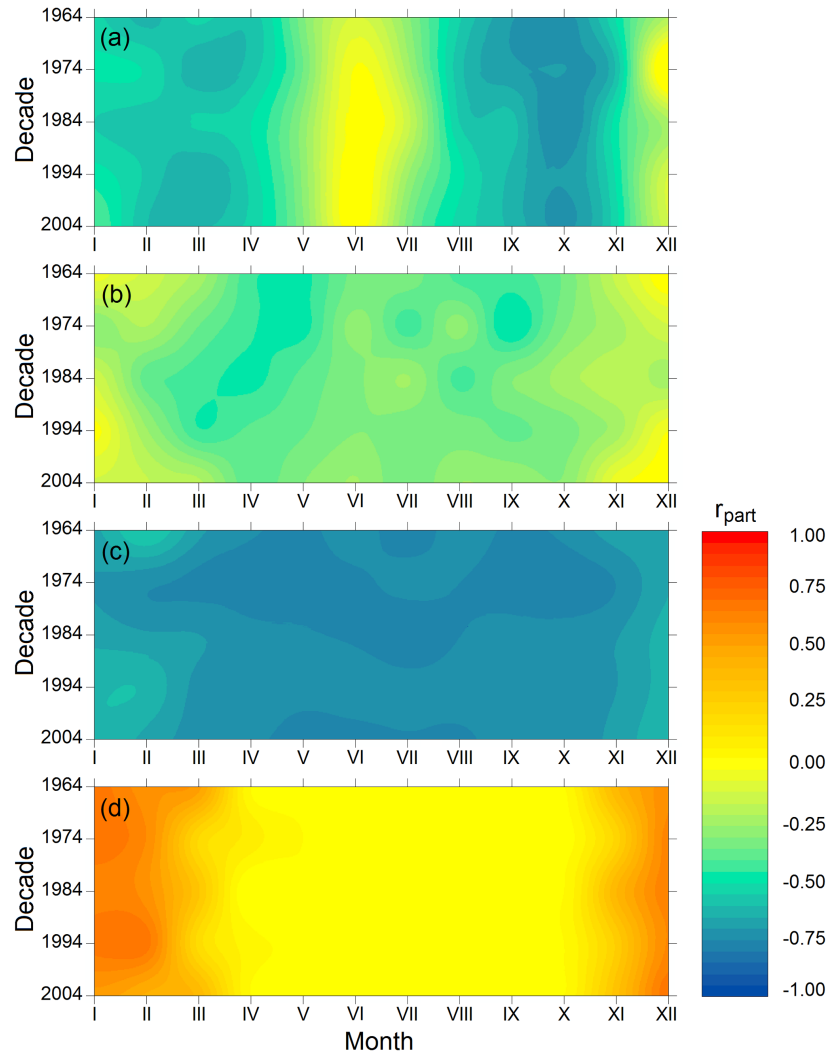

Figure 3. Partial correlation coefficients $\left(r_{\text {part }}\right)$ of the effects of (a) SZA, (b) TOC, (c) cloud cover, and (d) surface UV albedo on the daily doses in individual months and decades; the decades are labeled only by their initial years.

most affected by SZA, cloud cover, and then by TOC and surface UV albedo $\left(r_{\text {part }}=-0.88,-0.59,-0.35\right.$, and 0.22 , respectively). During the individual months, cloud cover was the most important factor affecting the EUV radiation daily doses; TOC had the most pronounced effect in April. Furthermore, the effect of SZA, TOC, cloud cover and surface UV albedo varied throughout the study period. The effect of SZA did not change much over the decades; it ranged from $r_{\text {part }}=-0.84$ to $r_{\text {part }}=-0.87$. It was the strongest in the months when SZA is the most variable (spring and autumn months), but it had insignificant effect in the months near the solstices (Fig. 3a). The effect of TOC was most pronounced in the decade 1984-1993 ( $\left.r_{\text {part }}=-0.34\right)$, when the thinning of the ozone layer was most significant. Figure $3 \mathrm{~b}$ shows TOC had the strongest effect on the daily EUV radiation doses in the spring months, but also in late summer and early autumn, especially in the decades 1984-1993 and 1994-2003. The effect of cloud cover was the strongest in the decade 1994-2003 ( $\left.r_{\text {part }}=-0.63\right)$, while the weakest relationship was found in the decade 2004-2013 $\left(r_{\text {part }}=-0.57\right)$. As shown in Fig. 3c, the effect of cloud cover also differed in individual seasons, with the strongest influence in 

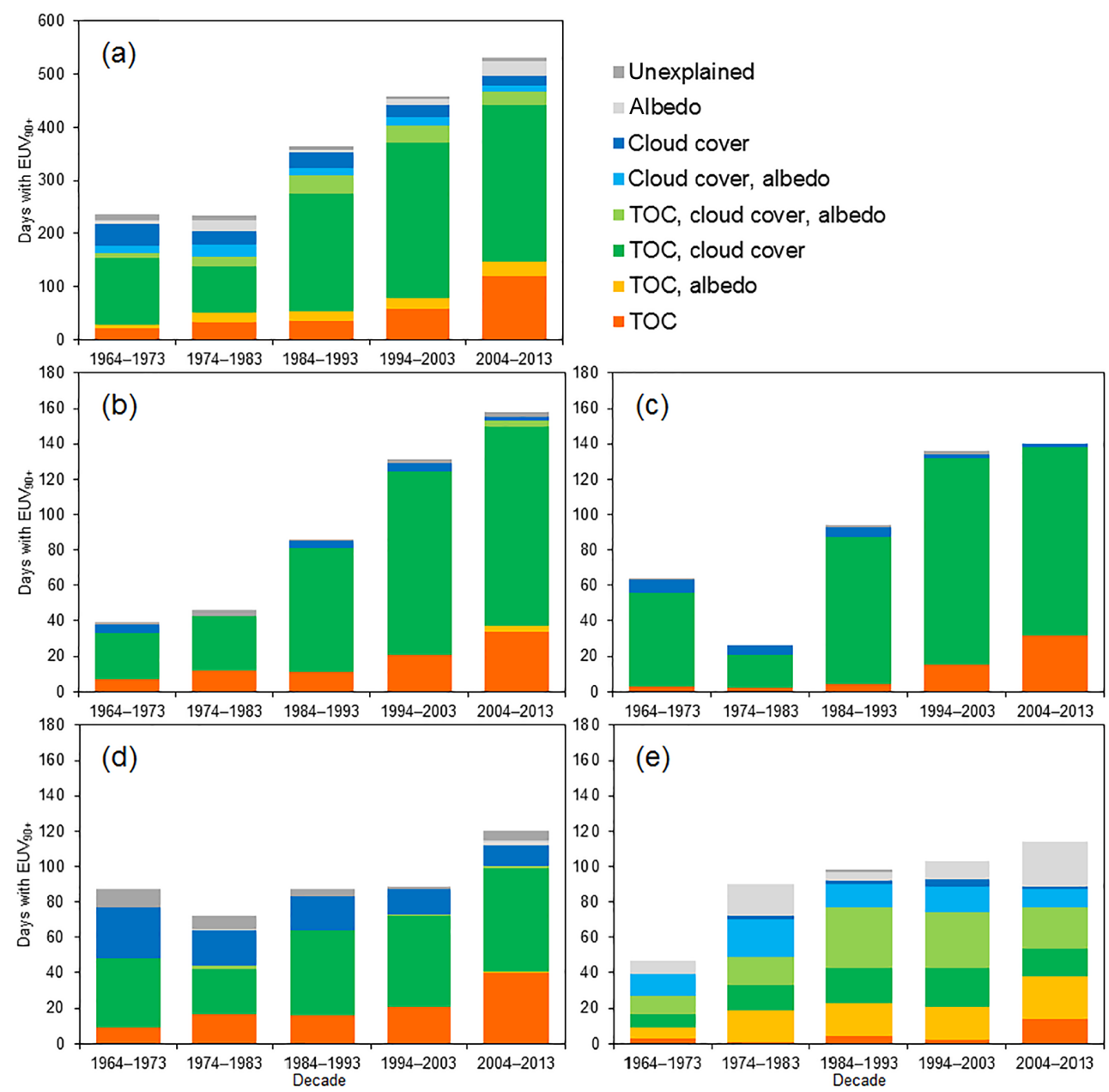

Figure 4. The number of days with $\mathrm{EUV}_{90+}$ in the individual studied decades, and their explanation by TOC, cloud cover, albedo, and their combinations, for (a) the entire year, (b) spring, (c) summer, (d) autumn, and (e) winter.

the summer months of the decades 1964-1973, 1984-1993 and 2004-2013, and in the spring and autumn months of the decade 1974-1983. Surface UV albedo (Fig. 3d) was only affecting the EUV radiation doses in winter months; therefore, its effect throughout the decades was the weakest of all the studied variables $\left(r_{\text {part }}\right.$ ranging from 0.16 in the decade 1984-1993 to 0.25 in the decade 2004-2013).

The results concur with similar studies performed at other European locations, showing that TOC is the main driver of long-term EUV radiation changes, while SZA and cloud cover are the dominant factors affecting EUV radiation in the short term (Den Outer et al., 2010; Herman, 2010; De Bock et al., 2014). The changes in EUV radiation in the 1970s have been attributed to cloud cover variability, which is in accord with the high $r_{\text {part }}$ shown in Fig. 3c. The latter increase in EUV radiation doses was caused mainly by the strong total ozone loss. For example, in the late 1980s to early 2000s, the changes in TOC were responsible for the majority of changes in EUV radiation in Austria, especially in spring (Rieder et al., 2008). At the beginning of the new millennium, the ef- fect of cloud cover grew stronger in contrast to the previous decades (Krzyścin et al., 2004).

\subsection{Very high erythemal UV radiation daily doses}

The EUV radiation doses reconstructed for the Hradec Králové observatory within the chosen study period have been examined with regards to very high values $\left(\mathrm{EUV}_{90+}\right)$. Based on the 90th percentile of each month (see Sect. 4 and Table 3), a total of 1827 days with $\mathrm{EUV}_{90+}$ were selected for further analysis. In the period 1964-2013, the number of days with $\mathrm{EUV}_{90+}$ increased by $8.1 \pm 1.1$ days (i.e., $22 \pm 3 \%)$ per decade $\left(r^{2}=55 \%\right)$, but the increase was variable in time. In the 1960s and the beginning of the 1970s, the number of days with $\mathrm{EUV}_{90+}$ decreased, followed by a steep increase, which stopped at the end of the 1990s. The number of days with EUV $_{90+}$ increased again at the beginning of the 21st century. The general increase in days with EUV $_{90+}$ was statistically significant in all seasons except autumn, while it was most evident in spring (an increase by 
Table 5. Partial correlation coefficients of the effect of SZA, TOC, cloud cover, and UV albedo on EUV radiation daily doses and their monthly means throughout the period 1964-2013; asterisks mark statistically significant correlations $(\alpha=0.05)$.

\begin{tabular}{lrrrr|rrrr}
\hline \multicolumn{5}{c|}{ Daily EUV radiation doses } & \multicolumn{4}{|c}{ Monthly mean EUV radiation doses } \\
\hline Period & SZA & TOC & Cloud cover & UV albedo & SZA & TOC & Cloud cover & UV albedo \\
\hline Year & $-0.88^{*}$ & $-0.35^{*}$ & $-0.59^{*}$ & $0.22^{*}$ & $-0.96^{*}$ & $-0.59^{*}$ & $-0.35^{*}$ & $0.48^{*}$ \\
I & $-0.66^{*}$ & $-0.37^{*}$ & $-0.78^{*}$ & $0.65^{*}$ & - & $-0.64^{*}$ & $-0.41^{*}$ & $0.92^{*}$ \\
II & $-0.72^{*}$ & $-0.45^{*}$ & $-0.77^{*}$ & $0.60^{*}$ & - & $-0.77^{*}$ & $-0.80^{*}$ & $0.93^{*}$ \\
III & $-0.69^{*}$ & $-0.46^{*}$ & $-0.79^{*}$ & $0.38^{*}$ & - & $-0.79^{*}$ & $-0.84^{*}$ & $0.75^{*}$ \\
IV & $-0.60^{*}$ & $-0.51^{*}$ & $-0.79^{*}$ & 0.01 & - & $-0.81^{*}$ & $-0.86^{*}$ & -0.01 \\
V & $-0.35^{*}$ & $-0.49^{*}$ & $-0.80^{*}$ & - & - & $-0.81^{*}$ & $-0.85^{*}$ & - \\
VI & -0.05 & $-0.43^{*}$ & $-0.80^{*}$ & - & - & $-0.82^{*}$ & $-0.80^{*}$ & - \\
VII & $-0.29^{*}$ & $-0.43^{*}$ & $-0.81^{*}$ & - & - & $-0.76^{*}$ & $-0.90^{*}$ & - \\
VIII & $-0.58^{*}$ & $-0.46^{*}$ & $-0.79^{*}$ & - & - & $-0.85^{*}$ & $-0.79^{*}$ & - \\
IX & $-0.69^{*}$ & $-0.45^{*}$ & $-0.79^{*}$ & - & - & $-0.74^{*}$ & $-0.87^{*}$ & - \\
X & $-0.77^{*}$ & $-0.36^{*}$ & $-0.79^{*}$ & -0.01 & - & $-0.54^{*}$ & $-0.87^{*}$ & -0.04 \\
XI & $-0.62^{*}$ & $-0.28^{*}$ & $-0.77^{*}$ & $0.33^{*}$ & - & $-0.39^{*}$ & $-0.79^{*}$ & $0.47^{*}$ \\
XII & $-0.22^{*}$ & $-0.31^{*}$ & $-0.77^{*}$ & $0.64^{*}$ & - & $-0.57^{*}$ & $-0.73^{*}$ & $0.89^{*}$ \\
\hline
\end{tabular}

$3.2 \pm 0.5$ days in 10 years, $\left.r^{2}=47 \%\right)$. The factors affecting the occurrence of days with $\mathrm{EUV}_{90+}$ in all the studied decades are shown in Fig. 4, while the thresholds of these factors are described in Sect. 4. There was a statistically significant negative correlation of the yearly number of days with $\mathrm{EUV}_{90+}$ and mean yearly TOC $\left(r^{2}=61 \%\right)$ and with mean yearly cloud cover $\left(r^{2}=23 \%\right)$. The effect of TOC was strongest in spring $\left(r^{2}=53 \%\right)$ and weakest, but still statistically significant, in winter $\left(r^{2}=8 \%\right)$. Cloud cover showed the most significant effect in summer $\left(r^{2}=17 \%\right)$ and its effect was insignificant in autumn. $82 \%$ of days with EUV $_{90+}$ were recorded when the TOC was low (less than the 50th percentile of each month), but in spring and summer this value exceeded $94 \%$. Moreover, $74 \%$ of days with $\mathrm{EUV}_{90+}$ occurred when the daily mean cloud cover was 4 octas or lower; in summer this value increased to $87 \%$. High albedo was observed in $19 \%$ of the days with $\mathrm{EUV}_{90+}$, in winter in $74 \%$ of days with $\mathrm{EUV}_{90+}$. Most of the unexplained days with EUV $_{90+}$ occurred in autumn, when the studied factors were also less likely to combine. Therefore, the yearly number of days with $\mathrm{EUV}_{90+}$ is both in total and in all seasons affected more by TOC than by cloud cover. The increase in days with high EUV radiation doses was also observed in Austria and Switzerland, especially in the 1990s. Low TOC and its combination with partly cloudy or cloudless skies were also the most frequent causes of days with high EUV radiation doses (Rieder et al., 2010).

The relationship between the very high EUV radiation doses and the atmospheric circulation was studied using principal component analysis (PCA) and the Arctic Oscillation (AO) and North Atlantic Oscillation (NAO) indices. The first and second PCA modes (Fig. 5) show that the occurrence of days with $\mathrm{EUV}_{90+}$ is linked to $\mathrm{NAO}, \mathrm{AO}$, and the shape and strength of the Arctic circumpolar vortex. The $1000 \mathrm{hPa}$ first component clearly indicates the effect of the Azores High
Table 6. The correlation coefficients between the $1000 \mathrm{hPa}$ first PCA component and the NAO and AO indices; asterisks mark statistically significant correlations $(\alpha=0.05)$.

\begin{tabular}{lll}
\hline Season & NAO & AO \\
\hline Spring & $-0.54^{*}$ & $-0.59^{*}$ \\
Summer & -0.43 & $-0.51^{*}$ \\
Autumn & -0.35 & $-0.51^{*}$ \\
Winter & $-0.63^{*}$ & $-0.68^{*}$ \\
\hline
\end{tabular}

promontory in central Europe. The intensities of the Azores High and Icelandic Low are statistically interconnected (Wallace and Gutzler, 1981); therefore, both these pressure systems are linked to the occurrence of days with $\mathrm{EUV}_{90+}$. This can be supported by the statistically significant negative correlation coefficients between the $1000 \mathrm{hPa}$ first PCA component and the AO and NAO indices (Table 6). Although the relationship between air pressure systems and shortwave radiation is expressed mostly through the redistribution of clouds (Chiacchio and Wild, 2010), the results presented in this study indicate that low TOC is the dominant factor affecting the incidence of days with $\mathrm{EUV}_{90+}$. Low TOC occurs mostly during the NAO positive phase, which leads to stationary planetary waves, stronger zonal winds, and therefore a colder Arctic circumpolar vortex (Orsolini and Limpasuvan, 2001; Schnadt and Dameris, 2003). A cold polar vortex allows the development of polar stratospheric clouds, which leads to greater ozone depletion over the Northern Hemisphere (Harris et al., 2010). Moreover, during the positive NAO phase, a ridge of high air pressure develops over central Europe (Hurrell, 1995), which usually leads to little cloudiness, enabling a more frequent occurrence of days with $\mathrm{EUV}_{90+}$. The second $1000 \mathrm{hPa}$ PCA mode can be associated with the spatial 


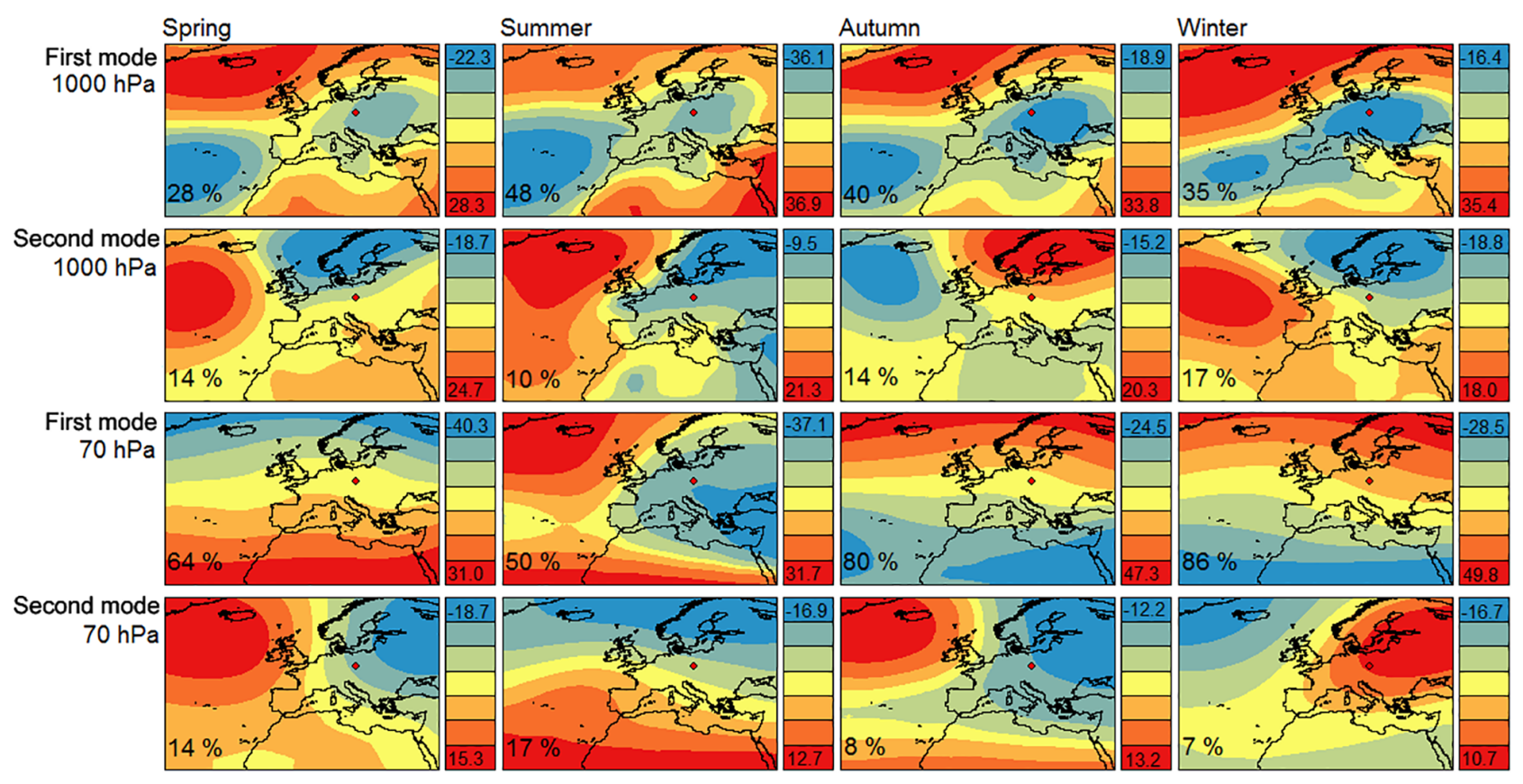

Figure 5. The values of the first and second PCA modes of the 1000 and $70 \mathrm{hPa}$ geopotential heights for the days with EUV $90+$ in spring, summer, autumn, and winter (represented by the color legend on the right). Variability explained by each of the modes is indicated by the relative value in the bottom-left corner. The red dot marks the location of the Hradec Králové observatory.

pattern of high- and low-air-pressure areas south of Iceland and over Scandinavia. It can therefore be understood as the meridional airflow over the North Sea, either from or to the area of the Arctic circumpolar vortex.

The zonal character of the $70 \mathrm{hPa}$ first PCA mode in spring, autumn, and winter (Fig. 5) is linked to the strength of the Arctic circumpolar vortex. It seems to be the dominant stratospheric factor affecting the amount of ozone and therefore also the occurrence of days with $E_{U V} V_{90+}$ in these seasons. The Arctic circumpolar vortex decays in summer (Harvey et al., 2002), so the polar front cyclones can easily penetrate it, upset its symmetry, and affect the transport of ozone from the lower latitudes. Subsequently, this situation also favors the occurrence of days with $\mathrm{EUV}_{90+}$, which is especially affected by the influx of air from the southwest. The first PCA mode in summer and the second PCA mode in other seasons document this meridional component of atmospheric circulation, which allows ozone-poor air from the tropics to flow into central Europe as well as high-latitude regions. Moreover, these conditions are often accompanied by high air pressure leading to clear-sky or partly cloudy situations (Stick et al., 2006), thus having major influence on the incidence of high EUV radiation doses.

\section{Concluding remarks}

In this paper, the reconstruction and analysis of the EUV radiation daily dose time series from the Solar and Ozone
Observatory in Hradec Králové (Czech Republic) have been performed for the period 1964-2013. The time series was reconstructed using a radiative transfer model and an empirical relationship of the observed EUV and global solar radiation. The model was verified based on EUV radiation observations of the Brewer spectrophotometer B184 in the period 20052013. The selected methods applied for the time series reconstruction gave the best estimates of EUV radiation using the input and validation data (solar radiation, TOC, albedo, AOD, water vapor column) available for the given location. This approach significantly improved the quality and accuracy of the reconstructed EUV radiation time series, which was extended to the entire 1964-2013 period.

The study focused on the evaluation of general variations and long-term trends, as well as the factors affecting EUV radiation doses. The results showed that the EUV radiation daily doses were characterized by large variability and changeable trends in the individual decades. Due to increasing cloud cover and TOC fluctuations, the EUV radiation doses slightly decreased in the 1960s and 1970s. The rapid increase in EUV radiation daily doses, observed in the 1980s and 1990s, was linked to the TOC decline, supporting the findings of previous studies on TOC variation and past EUV radiation doses. At the beginning of the new millennium, EUV radiation fluctuations were mostly attributed to the changes in cloud cover. Moreover, the results confirmed that the annual means of EUV radiation daily doses are most affected by the changes in TOC, while the monthly means are 
most influenced by cloud cover or, in winter months, by surface UV albedo. The daily EUV radiation doses were mainly affected by SZA, but the effect of SZA was insignificant in the summer and winter solstice months.

The number of days with very high EUV radiation doses $\left(\mathrm{EUV}_{90+}\right)$ increased significantly throughout the study period, especially in the spring months. The occurrence of days with $\mathrm{EUV}_{90+}$ was mostly affected by low TOC, but clear or partly cloudy skies also had a significant role, especially in summer. In winter months, the increased surface albedo also significantly affected the occurrence of days with $\mathrm{EUV}_{90+}$. Therefore, it was clearly indicated that the main factors affecting the long-term changes of the occurrence of days with $\mathrm{EUV}_{90+}$ are seasonally dependent. For the first time, the relationship between the high EUV radiation doses and synoptic weather situations was evaluated using principal component analysis and large-scale atmospheric circulation patterns at the 1000 and $70 \mathrm{hPa}$ geopotential heights. The results suggest that the days with $\mathrm{EUV}_{90+}$ occur most likely during the positive NAO phase, when the Azores High promontory reaches over the area of central Europe. These conditions lead to a cold and stable Arctic circumpolar vortex, which contributes to accelerated ozone depletion over the Arctic region. Moreover, a high air pressure ridge over central Europe frequently causes cloudless skies and subsequently higher EUV radiation doses. In summer, the influx of ozone-poor air from the southwest in the upper levels of the atmosphere can also contribute to the occurrence of days with $\mathrm{EUV}_{90+}$.

Compared to the existing long-term datasets, the reconstructed EUV radiation time series is one of the longest in central Europe, and therefore it can be used for the investigation of the long-term photobiological effects on organisms, or for skin cancer research. Furthermore, the study brought valuable knowledge of regional EUV radiation variability and trends in the past decades. It especially provided a closer look at the days with very high EUV radiation doses and their relationships with other variables, including the atmospheric circulation patterns. Nevertheless, the EUV radiation doses and the trends described in this study might be significantly affected by ozone layer recovery and by the changes in atmospheric circulation patterns predicted by the atmospheric chemistry and climate models (e.g., Inglesias-Suarez et al., 2016). It must, however, be anticipated that the scope of the study has not allowed to take into account other possibly important factors, such as the El Niño-Southern Oscillation or Quasi-Biennial Oscillation, which will be considered in further research.

Data availability. The data used for this study that were obtained at the Solar and Ozone Observatory, Hradec Králové (SOO-HK), and other Czech Hydrometeorological Institute (CHMI) stations are property of CHMI, and therefore can not be made publicly accessible. Data will be provided upon request by Ladislav Metelka, the head of SOO-HK (metelka@chmi.cz). Data on the total ozone content and water vapor column have been taken from the ERA40 and ERA-Interim reanalysis issued by the European Centre for Medium-Range Weather Forecasts; the aerosol optical depth data have been provided by the NASA Goddard Earth Sciences Data and Information Services Center (at http://giovanni.gsfc.nasa. gov); and the geopotential height fields were acquired from the NCEP/NCAR reanalysis of the Earth System Research Laboratory, National Oceanic and Atmospheric Administration (https://www. esrl.noaa.gov/psd/data/reanalysis/reanalysis.shtml).

Author contributions. KL, LM, and KČ drew up the research idea; KC and LM prepared the data; MS wrote the libRadtran script; and KC carried out the time series reconstruction and the analyses. KC and KL prepared the manuscript with contributions from LM.

Competing interests. The authors declare that they have no conflict of interest.

Special issue statement. This article is part of the special issue "Quadrennial Ozone Symposium 2016 - Status and trends of atmospheric ozone (ACP/AMT inter-journal SI)". It is a result of the Quadrennial Ozone Symposium 2016, Edinburgh, United Kingdom, 4-9 September 2016.

Acknowledgements. The research was supported by the project of the Czech Hydrometeorological Institute no. 03461022 "Monitoring of the ozone layer and UV radiation in Antarctica", which is funded by the State Environmental Fund of the Czech Republic, and by the project of Masaryk University MUNI/A/1419/2016. The article outputs contribute to the CzechPolar2 and ECOPOLARIS working group (CZ.02.1.01/0.0/0.0/16_013/0001708).

Edited by: Sophie Godin-Beekmann

Reviewed by: two anonymous referees

\section{References}

Alados-Arboledas, L., Alados, I., Foyo-Moreno, I., Olmo, F. J., and Alcántara, A.: The influence of clouds on surface UV erythemal irradiance, Atmos. Res., 66, 273-290, 2003.

Ambaum, M. H., Hoskins, B. J., and Stephenson, D. B.: Arctic Oscillation or North Atlantic Oscillation?, J. Climate, 14, 34953507, 2001.

Anav, A., Moriconi, M. L., Giannoccolo, S., and DiMeno, M.: Field measurements of the global UV-B radiation: a comparison between a broad-band radiometer and a Brewer spectrophotometer, Il Nuovo Cimento, 19, 505-516, 1996.

Bais. A. F., McKenzie, R. L., Bernhard, G., Aucamp, P. J., Ilyas, M., Madronich, S., and Tourpali, K.: Ozone depletion and climate change: impacts on UV radiation, Photochem. Photobiol. Sci., 14, 19-52, 2015.

Bilbao, J., Román, R., de Miguel, A., and Mateos, D.: Long-term solar erythemal UV irradiance data reconstruction in Spain us- 
ing a semiempirical method, J. Geophys. Res., 116, D22211, https://doi.org/10.1029/2011JD015836, 2011.

Blumthaler, M. and Ambach, W.: Solar UV-B albedo of various surfaces, Photochem. Photobiol., 48, 85-88, 1988.

Caldwell, M. M., Bornman, J. F., Ballaré, C. L., Flint, S. D., and Kulandaivelu, G.: Terrestrial ecosystems, increased solar ultraviolet radiation, and interactions with other climate change factors, Photochem. Photobiol. Sci., 6, 252-266, 2007.

Chiacchio, M. and Wild, M.: Influence of NAO and clouds on long-term seasonal variations of surface solar radiation in Europe, J. Geophys. Res., 115, D00D22, https://doi.org/10.1029/2009JD012182, 2010.

Cleveland, W. S.: Robust locally weighted regression and smoothing scatterplots, J. Am. Stat. Assoc., 368, 829-836, 1979.

De Bock, V., De Backer, H., Van Malderen, R., Mangold, A., and Delcloo, A.: Relations between erythemal UV dose, global solar radiation, total ozone column and aerosol optical depth at Uccle, Belgium, Atmos. Chem. Phys., 14, 12251-12270, https://doi.org/10.5194/acp-14-12251-2014, 2014.

Dee, D. P., Uppala, S. M., Simmons, A. J., Berrisford, P., Poli, P., Kobayashi, S., Andrae, U., Balmaseda, M. A., Balsamo, G., Bauer, P., Bechtold, P., Beljaars, A. C. M., van de Berg, L., Bidlot, J., Bormann, N., Delsol, C., Dragani, R., Fuentes, M., Geer, A. J., Haimberger, L., Healy, S. B., Hersbach, H., Hólm, E. V., Isaksen, L., Kållberg, P., Köhler, M., Matricardi, M., McNally, A. P., Monge-Sanz, B. M., Morcrette, J.-J., Park, B.-K., Peubey, C., de Rosnay, P., Tavolato, C., Thépaut, J.-N., and Vitart, F.: The ERA-Interim reanalysis: configuration and performance of the data assimilation system, Q. J. Roy. Meteor. Soc., 137, 553-597, 2011.

Den Outer, P. N., Slaper, H., Kaurola, J., Lindfors, A., Kazantzidis, A., Bais, A. F., Feister, U., Junk, J., Janouch, M., and Josefsson, W.: Reconstructing of erythemal ultraviolet radiation levels in Europe for the past 4 decades, J. Geophys. Res., 115, D10102, https://doi.org/10.1029/2009JD012827, 2010.

De Paula Corrêa, M. and Ceballos, J. C.: UVB surface albedo measurements using biometers, Rev. Bras. Geof., 26, 411-416, 2008.

Diffey, B. L.: Solar ultraviolet radiation effects on biological systems, Phys. Med. Biol., 36, 299-328, 1991.

Farman, J. C., Gardiner, B. G., and Shanklin, J. D.: Large losses of total ozone in Antarctica reveal seasonal $\mathrm{ClO}_{x} / \mathrm{NO}_{x}$ interaction, Nature, 315, 207-210, 1985.

Feister, U. and Grewe, R.: Spectral albedo measurements in the UV and visible region over different types of surfaces, Photochem. Photobiol., 62, 736-744, 1995.

Gardiner, B. G., Webb, A. R., Bais, A. F., Blumthaler, M., Dirmhirn, I., Forster, P., Gillotay, D., Henriksen, K., Huber, M., Kirsch, P. J., Simon, P. C., Svenoe, T., Weihs, P., and Zerefos, C. S.: European intercomparison of ultraviolet spectroradiometers, Environ. Technol., 14, 25-43, 1993.

Hadzimustafic, J., Simic, S., and Fitzka, M.: UV-Radiation in the Past: Reconstruction and Long-term Changes in Austria, AIP Conf. Proc., 1531, 868-871, 2013.

Harris, N. R. P., Kyrö, E., Staehelin, J., Brunner, D., Andersen, S.B., Godin-Beekmann, S., Dhomse, S., Hadjinicolaou, P., Hansen, G., Isaksen, I., Jrrar, A., Karpetchko, A., Kivi, R., Knudsen, B., Krizan, P., Lastovicka, J., Maeder, J., Orsolini, Y., Pyle, J. A., Rex, M., Vanicek, K., Weber, M., Wohltmann, I., Zanis, P., and Zerefos, C.: Ozone trends at northern mid- and high lati- tudes - a European perspective, Ann. Geophys., 26, 1207-1220, https://doi.org/10.5194/angeo-26-1207-2008, 2008.

Harris, N. R. P., Lehmann, R., Rex, M., and von der Gathen, P.: A closer look at Arctic ozone loss and polar stratospheric clouds, Atmos. Chem. Phys., 10, 8499-8510, https://doi.org/10.5194/acp-10-8499-2010, 2010.

Harvey, V. L., Pierce, R. B., Fairlie, T. D., and Hitchman, M. H.: A climatology of stratospheric polar vortices and anticyclones, J. Geophys. Res., 107, 4442, https://doi.org/10.1029/2001JD001471, 2002.

Herman, J. R.: Global increase in UV irradiance during the past 30 years (1979-2008) estimated from satellite data, J. Geophys. Res., 115, D04203, https://doi.org/10.1029/2009JD012219, 2010.

Hofmann, D. J., Johnson, B. J., and Oltmans, S. J.: Twenty-two years of ozonesonde measurements at the South Pole, Int. J. Remote Sens., 30, 3995-4008, 2009.

Hood, L. L. and Soukharev, B. E.: Interannual variation of total ozone at northern midlatitudes correlated with stratospheric EP flux and potential vorticity, J. Atmos. Sci., 62, 3724-3740, 2005.

Hülsen, G., Gröbner, J., Bais, A., Blumthaler, M., Disterhoft, P., Johnsen, B., Lantz, K. O., Meleti, C., Schreder, J., Vilaplana Guerrero, J. M., and Ylianttila, L.: Intercomparison of erythemal broadband radiometers calibrated by seven UV calibration facilities in Europe and the USA, Atmos. Chem. Phys., 8, 4865-4875, https://doi.org/10.5194/acp-8-4865-2008, 2008.

Hurrell, J. W.: Decadal Trends in the North Atlantic Oscillation: Regional Temperatures and Precipitation, Science, 269, 676-679, 1995.

Iglesias-Suarez, F., Young, P. J., and Wild, O.: Stratospheric ozone change and related climate impacts over 1850-2100 as modelled by the ACCMIP ensemble, Atmos. Chem. Phys., 16, 343-363, https://doi.org/10.5194/acp-16-343-2016, 2016.

Kalnay, E., Kanamitsu, M., Kistler, R., Collins, W., Deaven, D., Gandin, L., Iredell, M., Saha, S., White, G., Woollen, J., Zhu, Y., Chelliah, M., Ebisuzaki, W., Higgins, W., Janowiak, J., Mo, K. C., Ropelewski, C., Wang, J., Leetmaa, A., Reynolds, R., Jenne, R., and Joseph, D.: The NCEP/NCAR 40-year reanalysis project, B. Am. Meteorol. Soc., 77, 437-470, 1996.

Kerr, J. B.: Understanding the factors that affect surface ultraviolet radiation, Opt. Eng., 44, 041002, https://doi.org/10.1117/1.1886817, 2005.

Kirchner, I. and Peters, D.: Modelling the wintertime response to upper tropospheric and lower stratospheric ozone anomalies over the North Atlantic and Europe, Ann. Geophys., 21, 2107-2118, https://doi.org/10.5194/angeo-21-2107-2003, 2003.

Krüger, O. and Graß1, H.: The indirect aerosol effect over Europe, Geophys. Res. Lett., 29, 1925, https://doi.org/10.1029/2001GL014081, 2002.

Krzyscin, J. W. and Borkowski, J. L.: Variability of the total ozone trend over Europe for the period 1950-2004 derived from reconstructed data, Atmos. Chem. Phys., 8, 2847-2857, https://doi.org/10.5194/acp-8-2847-2008, 2008.

Krzyścin, J. W. and Rajewska-Więch, B.: Specific variability of total ozone over Central Europe during spring and summer in the period 1979-2014, Int. J. Climatol., 35, 1-11, 2015.

Krzyścin, J. W., Degórska, M., and Rajewska-Więch, B.: Seasonal acceleration of the rate of total ozone decreases over Central Eu- 
rope: impact of tropopause height changes, J. Atmos. Sol.-Terr. Phy., 60, 1755-1762, 1998.

Krzyscin, J. W., Eerme, K., and Janouch, M.: Long-term variations of the UV-B radiation over Central Europe as derived from the reconstructed UV time series, Ann. Geophys., 22, 1473-1485, https://doi.org/10.5194/angeo-22-1473-2004, 2004.

Krzyścin, J. W., Sobolewski, P. S., Jarosławski, J., Podgórski, J., and Rajewska-Więch, B.: Erythemal UV observations at Belsk, Poland, in the period 1976-2008: data homogenization, climatology, and trends, Acta Geophys., 59, 155-182, 2011.

Lindfors, A., Kaurola, J., Arola, A., Koskela, T., Lakkala, K., Josefsson, W., Olseth, J. A., and Johnsen, B.: A method for reconstruction of past UV radiation based on radiative transfer modeling: Applied to four stations in northern Europe, J. Geophys. Res., 112, D23201, https://doi.org/10.1029/2007JD008454, 2007.

Lucas, R., McMichael, T., Smith, W., and Armstrong, B.: Solar ultraviolet radiation: Global burden of disease from solar ultraviolet radiation, World Health Organization, Geneva, Switzerland, 2006.

Mayer, B. and Kylling, A.: Technical note: The libRadtran software package for radiative transfer calculations - description and examples of use, Atmos. Chem. Phys., 5, 1855-1877, https://doi.org/10.5194/acp-5-1855-2005, 2005.

McKinlay, A. F. and Diffey, B. L.: A reference spectrum for ultraviolet induced erythema in human skin, CIE J., 6, 21-27, 1987.

Orsolini, Y. J. and Limpasuvan, V.: The North Atlantic Oscillation and the occurrences of ozone miniholes, Geophys. Res. Lett., 28, 4099-4102, 2001.

R Core Team: R: A language and environment for statistical computing, R Foundation for Statistical Computing, Vienna, Austria, 2014.

Remer, L. A., Kaufman, Y. J., Tanré, D., Mattoo, S., Chu, D. A., Martins, J. V., Li, R.-R., Ichoku, C., Levy, R. C., Kleidman, R. G., Eck, T. F., Vermote, E., and Holben, B. N.: The MODIS aerosol algorithm, products, and validation, J. Atmos. Sci., 62, 947-973, 2005.

Rieder, H. E., Holawe, F., Simic, S., Blumthaler, M., Krzyscin, J. W., Wagner, J. E., Schmalwieser, A. W., and Weihs, P.: Reconstruction of erythemal UV-doses for two stations in Austria: a comparison between alpine and urban regions, Atmos. Chem. Phys., 8, 6309-6323, https://doi.org/10.5194/acp-8-6309-2008, 2008.

Rieder, H. E., Staehlin, J., Weihs, P., Vuilleumier, L., Maeder, J. A., Holawe, F., Blumthaler, M., Lindfors, A., Peter, T., Simic, S., Spichtinger, P., Wagner, J. E., Walker, D., and Ribatet, M.: Relationship between high daily erythemal UV doses, total ozone, surface albedo and cloudiness: An analysis of 30 years of data from Switzerland and Austria, Atmos. Res., 90, 9-20, 2010.

Schnadt, C. and Dameris, M.: Relationship between North Atlantic Oscillation changes and stratospheric ozone recovery in the Northern Hemisphere in a chemistry-climate model, Geophys. Res. Lett., 30, 1487, https://doi.org/10.1029/2003GL017006, 2003.

Schwander, H., Koepke, P., Kaifel, A., and Seckmeyer, G.: Modification of spectral UV irradiance by clouds, J. Geophys. Res., 107, AAC 7-1-AAC 7-12, https://doi.org/10.1029/2001JD001297, 2002.

Seckmeyer, G., Pisulla, D., Glandorf, M., Henriques, D., Johnsen, B., Webb, A., Siani, A. M., Bais, A. F., Kjeldstad, B., Brogniez,
C., Lenoble, J., Gardiner, B., Kirsch, P., Koskela, T., Kaurola, J., Uhlmann, B., Slaper, H., de la Casiniere, A., Simic, S., and Carvalho, F.: Variability of UV irradiance in Europe, Photochem. Photobiol., 84, 172-179, 2008.

Solomon, S., Portmann, R. W., Sanders, R. W., and Daniel, J. S.: Absorption of solar radiation by water vapor, oxygen, and related collision pairs in the Earth's atmosphere, J. Geophys. Res., 103, 3847-3858, 1998.

Stick, C., Krüger, K., Schade, N. H., Sandmann, H., and Macke, A.: Episode of unusual high solar ultraviolet radiation over central Europe due to dynamical reduced total ozone in May 2005, Atmos. Chem. Phys., 6, 1771-1776, https://doi.org/10.5194/acp6-1771-2006, 2006.

Storch, H. von and Zwiers, F. W.: Statistical Analysis in Climate Research, Cambridge University Press, Cambridge, UK, 1999.

Thompson, D. W. J. and Wallace, J. M.: The Arctic Oscillation signature in the wintertime geopotential height and temperature fields, Geophys. Res. Lett., 25, 1297-1300, 1998.

Trepte, S. and Winkler, P.: Reconstruction of erythemal UV irradiance and dose at Hohenpeissenberg (1968-2001) considering trends of total ozone, cloudiness and turbidity, Theor. Appl. Climatol., 77, 159-171, 2004.

Uppala, S. M., Kållberg, P. W., Simmons, A. J., Andrae, U., Da Costa Bechtold, V., Fiorino, M., Gibson, J. K., Haseler, J., Hernandez, A., Kelly, G. A., Li, X., Onogi, K., Saarinen, S., Sokka, N., Allan, R. P., Andersson, E., Arpe, K., Balmaseda, M. A., Beljaars, A. C. M., Van De Berg, L., Bidlot, J., Bormann, N., Caires, S., Chevallier, F., Dethof, A., Dragosavac, M., Fisher, M., Fuentes, M., Hagemann, S., Hólm, E., Hoskins, B. J., Isaksen, L., Janssen P. A. E. M., Jenne, R., Mcnally, A. P., Mahfouf, J.-F., Morcrette, J.-J., Rayner, N. A., Saunders, R. W., Simon, P., Sterl, A., Trenberth, K. E., Untch, A., Vasiljevic, D., Viterbo, P., and Woollen, J.: The ERA-40 re-analysis, Q. J. Roy. Meteor. Soc., 131, 2961-3012, 2005.

Vallis, G. K., Gerber, E. P., Kushner, P. J., and Cash, B. A.: A Mechanism and Simple Dynamical Model of the North Atlantic Oscillation and Annual Modes, J. Atmos. Sci., 61, 264-280, 2004.

Vaníček, K.: Solar and Ozone Observatory Hradec Králové 19512001, Czech Hydrometeorological Institute, Prague, Czech Republic, 2001.

Vaníček, K.: Calibration history of the Dobson D074 and Brewer B098 Ozone Spectrophotometers, Czech Hydrometeorological Institute, Prague, Czech Republic, 2002.

Vaníček, K., Metelka, L., Skřivánková, P., and Staněk, M.: Longterm changes of the ozone layer over the Czech Republic, Czech Hydrometeorological Institute, Prague, Czech Republic, 2012.

Vaníček, K., Dubrovská, I., Metelka, L., and Pokorný, J.: Measurements of radiation balance components and long-term global solar radiation changes in the Czech Republic, Czech Hydrometeorological Institute, Prague, Czech Republic, 2015.

Wallace, J. M. and Gutzler, D. S.: Teleconnections in the Geopotential Height Field during the Northern Hemisphere Winter, Mon. Weather Rev., 109, 784-812, 1981.

Wibig, J.: Cloudiness variations in Łódź in the second half of the 20th century, Int. J. Climatol., 28, 479-491, 2008.

World Meteorological Organization (WMO): Guide to Meteorological Instruments and Methods of Observation, No. 8, World Meteorological Organization, 8th Edn., 2014. 
Ziemke, J. R., Chandra, S., Herman, J., and Varotsos, C.: Erythemally weighted UV trends over northern latitudes derived from Nimbus 7 TOMS measurements, J. Geophys. Res., 105, 7373$7382,2000$.
Zvyagintsev, A. M., Vargin, P. N., and Peshin, S.: Total ozone variations and trends during the period 1979-2014, Atmos. Ocean. Opt., 28, 575-584, 2015. 